\title{
Revista Digital de Direito Administrativo
}

FACULDADE DE DiREITO DE RIBEIRÃo PRETO - FDRP

UNIVERSIDADE DE SÃo PAULO- USP

\author{
Seção: Artigos Científicos
}

\section{Procedimientos administrativos telemáticos \\ Estudio de caso: el uso de Tecnologías de Información y Comunicación en la Escuela Nacional de la Magistratura de Venezuela}

\author{
Telematic administratives procedures \\ Case study: the use of Information and Communicaction Technology at National School of Judiciary \\ of Venezuela
}

\section{Gustavo Adolfo Amoni}

\begin{abstract}
Resumo: A Escola Nacional da Magistratura da Venezuela (ENM) é um órgão administrativo judiciário localizado em Caracas, com compêtencia nacional. Para cumprir sua missão, deve usar tecnologias da informação e comunicação. No artigo, parte-se de uma análise dos processos, bem como dos atos administrativos da ENM. Em seguida, abordam-se os argumentos a favor e contra a suficiencia da legislação atual para usar as TIC na Administração, com especial destaque das formalidades que devem ser cumpridas de acordo com diversos textos legais do século XXI que modernizaram a lei de 1981 e, ao final, propõe-se como digitalizar a ENM.
\end{abstract}

Palavras-chave: processo administrativo, Escola Nacional da Magistratura, ato administrativo, telemática, tecnologias da informaçao e comunicação.

\begin{abstract}
The National School of Judiciary of Venezuela (NSJ) is a judicial agency with administrative responsabilities located in Caracas with nationwide competencies. To fulfill its mission, it shall use Information and Communication Technologies (ICT). This paper begins analyzing NSJ administrative procedures and acts. Then, the study is addressed toward the arguments, in favor and against, sufficiency of current legislation to use ICT in government, specially, considering the formalities that must be completed according to different 21st century laws that modernized the law of 1981 . Finally, it is proposed how to modernize the NSJ.
\end{abstract}

Keywords: administrative procedure, National School of Judiciary, administrative act, telematic, information and communication technologies.

Disponível no URL:www.revistas.usp.br/rdda

DOI: http://dx.doi.org/10.11606/issn.2319-0558.v7n1p27-60

Este conteúdo está protegido pela lei de direitos autorais. É permitida a reprodução, desde que indicada afonte como "Conteúdo da Revista Digital de Direito Administrativo".A RDDA constitui periódico científico da FDRP/USP, cuja função édivulgar gratuitamente pesquisa na área de direito administrativo. Editor responsável: Professor Associado Thiago Marrara. 


\title{
PROCEDIMIENTOS ADMINISTRATIVOS TELEMÁTICOS - ESTUDIO DE CA- SO: EL USO DE TECNOLOGÍAS DE INFORMACIÓN Y COMUNICACIÓN EN
} LA ESCUELA NACIONAL DE LA MAGISTRATURA DE VENEZUELA

\author{
Gustavo Adolfo Amoni*
}

Sumário: 1 Introdución; 2 Generalidades de los procedimientos administrativos en la ENM: el procedimiento, el expediente y el punto de cuenta administrativos; 2.1 Procedimientos administrativos telemáticos; $2.2 \mathrm{El}$ expediente administrativo digital; $2.3 \mathrm{EI}$ punto de cuenta; 2.3.1 El punto de cuenta em la práctica de la ENM; 2.3.2 El punto de cuenta digital; 2.3.3 Naturaleza jurídica Del punto de cuenta en la ENM; 3 Los Procedimentos administrativos em las diversas unidades administrativas de la ENM; 3.1 Dirección de Docencia; 3.1.1 Actividades acadêmicas; 3.1.1.1 Foros y congresos; 3.1.1.2 Diplomados; 3.2 Dirección de Administración y Recursos Humanos; 3.2.1Contrataciones públicas o contrataciones del Estado 23; 3.2.2 Permisos e vacaciones; 3.2.3 Movimentos funcionariaeles y laborales; 3.2.4 Nómina; 3.3 Recursos documentales; 3.4 Secretaria; 3.5 Oficina de Cooperación Técnica; 4 Conclusiones; 5 Referencias bibliográficas

\section{Introducción}

La Escuela Nacional de la Magistratura (ENM) es uno de los tres órganos auxiliares del Tribunal Supremo de Justicia (TSJ). Su función es formar y capacitar a los servidores judiciales.

Con presencia en Caracas, pero con competencia nacional, tiene que acudir a las Tecnologías de Información y Comunicación (TIC) para poder cumplir con su deber. Esto implica, adecuar sus procedimientos administrativos, internos y externos, al uso de la firma electrónica, al mensaje de datos, expediente digital y al sistema de comunicación telemático.

En lo interno, la gestión de las diversas unidades administrativas se centra en los procedimientos a seguir para el ejercicio de sus atribuciones. Se trata de los trámi-

\footnotetext{
* Abogado en libre ejercicio, mención summa cum laude de la Universidad de Carabobo. Especialista cum laude en Derecho Administrativo de la Universidad Católica "Andrés Bello", Venezuela, donde ha sido profesor de postgrado en Derecho Administrativo y Derecho de las Telecomunicaciones. Es profesor de pre y postgrado de la Universidad Central de Venezuela, del Doctorado en Derecho de la Universidad Católica Santa Rosa y exdirector de la Escuela Nacional de la Magistratura, con casi 30 trabajos de investigación publicados en Argentina, Colombia, Ecuador, España, México, Uruguay y Venezuela, donde ha participado como ponente en congresos y foros sobre Derecho Informático.
} 
tes que le son irrelevantes al usuario pero que deben llevarse a cabo puesto que al tratarse de recursos del Estado, su manejo está limitado por reglas especiales, inspiradas por el principio de legalidad.

Por su parte, los procedimientos externos se refieren a las relaciones de la ENM con los usuarios, así como también con los órganos y entes públicos y privados, nacionales y extranjeros. En el primer grupo de relaciones se ubica la labor académica: docente, de investigación y extensión, y en el segundo, la celebración de convenios interinstitucionales.

La docencia abarca las clases, congresos, foros, talleres y en general toda la actividad que implica desarrollar, formalmente, el proceso de enseñanza-aprendizaje. La investigación incluye la generación de contenidos para ser usados en los programas de formación y que están disponibles en la revista Magistra, publicación científica, indexada y arbitrada, conformada por colaboraciones abiertas a cualquier persona y en especial, a servidores judiciales. Finalmente, la actividad de extensión alude a la atención jurídica comunitaria por parte de servidores de la ENM y de jueces y demás servidores judiciales cursantes de los programas de formación y capacitación permanentes.

Cumplir con estas tareas, de modo presencial tangible y valiéndose del papel y la tinta, implicaría una enorme carga económica que el uso de las TIC viene a aliviar. Así, los procedimientos administrativos no requieren papel ni tinta, ya que la escritura, su documentación, archivo, autenticidad y transmisión puede ser válidamente verificada usando TIC. Del mismo modo, las actividades docentes, de investigación y extensión, resultan ejecutables en un entorno digital.

Las leyes venezolanas se encargaron de dotar de soporte normativo a la actividad administrativa, de cualquiera de los órganos que ejercen el Poder Público, con independencia de la función principal que ejerzan; por tanto, los órganos judiciales, mas no jurisdiccionales, como la ENM (al igual que la Dirección Ejecutiva de la Magistratura y la Inspectoría General de Tribunales) pueden desarrollar las atribuciones que le impone el ordenamiento jurídico basándose en herramientas tecnológicas por las que se abaraten costos y se gane en simplicidad y rapidez en la respuesta, al tiempo que posibilitan la documentación de los procedimientos realizados, generando una memoria histórica que permita la revisión para fines de optimización de la gestión y de contraloría pública, que es uno de los principales temores de los servidores públicos en cuanto a la implantación de modelos "cero papel”.

\section{Generalidades de los procedimientos administrativos en la ENM: el procedimiento, el expediente y el punto de cuenta administrativos.}

La ENM requiere contratar servicios y adquirir bienes para su funcionamiento. Así mismo, cuenta con una nómina fija y de contratados para ocupar los cargos públicos y puestos de trabajo de los que dispone para cumplir con sus funciones. Ade- 
más, se relaciona con otros órganos y entes públicos y privados, nacionales y extranjeros; debe atender los requerimientos de formación y capacitación de todos los servidores judiciales, no solo de los jueces y demás integrantes de los tribunales; abre inscripciones para sus programas académicos, organiza sesiones de clase, emite constancias, celebra graduaciones, publica investigaciones vinculadas al Derecho y al quehacer judicial, y promueve programas de extensión a las comunidades.

Al tratarse de un órgano auxiliar del $\mathrm{TSJ}^{1}$, actuando en ejercicio de potestades administrativas, tales actividades pasan a ser reguladas por los principios ${ }^{2}$ y reglas administrativas en general $^{3}$, con las excepciones previstas en las normas especiales ${ }^{4}$.

En consecuencia, la actividad de la ENM está condicionada por la celebración de procedimientos, actos y contratos, de naturaleza administrativa; vale decir, con trámites que deben cumplir con requisitos formales cuya materialización, es jurídicamente válida, mediante el uso de TIC.

Se trata de una manera de modernizar el Estado, que implica cambiar la cultura administrativa, la adopción de nuevas técnicas de gestión y la redefinición de las relaciones entre estado y sociedad (MELO y OLIVEIRA, 2018, 116). No basta incluir TI y confiar en que estas guiarán el proceso de modernización, sino que se requiere voluntad y planificación (AMOROSO, 2011, 14).

\footnotetext{
1 “La Inspectoría General de Tribunales, la Inspectoría General de la Defensa Pública y la Escuela Nacional de la Magistratura son órganos dependientes jerárquica, organizativa y funcionalmente de la Sala Plena" (artículo 80 de la Ley Orgánica del Tribunal Supremo de Justicia).

${ }^{2}$ Artículo 141 de la Constitución de la República Bolivariana de Venezuela: “...honestidad, participación, celeridad, eficacia, eficiencia, transparencia, rendición de cuentas y responsabilidad en el ejercicio de la función pública, con sometimiento pleno a la ley y al derecho".

${ }^{3}$ Ley Orgánica de Procedimientos Administrativos (Gaceta Oficial № 2.818 Extraordinario del 1ㅇ de julio de 1981) (LOPA), Decreto con Rango, Valor y Fuerza de Ley Orgánica de la Administración Pública, (Gaceta Oficial $N^{\circ}$ Extraordinario 6.147 del 17 de noviembre de 2014) (DLOAP); Decreto con Rango, Valor y Fuerza de Ley de Simplificación de Trámites Administrativos (Gaceta Oficial N 6.149 Extraordinario, de fecha martes 18 de noviembre de 2014) (DLSTA); Ley del Estatuto de la Función Pública (Gaceta Oficial $N^{\circ} 37.482$, del 11 de julio de 2002) (LEFP), salvo los casos excluidos que se rigen por la Ley Orgánica del Trabajo, los Trabajadores y Trabajadoras (Gaceta Oficial $N^{\circ} 6.076$ Extraordinario, del 7 de mayo de 2012); Decreto con Rango, Valor y Fuerza de Ley sobre Acceso e Intercambio Electrónico de Datos, Información y Documentos entre los Órganos y Entes del Estado (Gaceta Oficial № 39.945 del 15 de junio de 2012) (DLI); Ley de Infogobierno (Gaceta Oficial $N^{\circ} 40.274$, del 17 de octubre de 2013) (LInf), entre otras como el Decreto con Rango, Valor y Fuerza de Ley de Contrataciones Públicas (Gaceta Oficial Nº 6.154 Extraordinario del 19 de noviembre 2014) (DLCP) y el Decreto con Rango, Valor y Fuerza de Ley Orgánica de Bienes Públicos (Gaceta Oficial de la República Bolivariana de Venezuela Nº 6.155 Extraordinario de fecha 19 de noviembre de 2014).

${ }^{4}$ Ley Orgánica del Tribunal Supremo de Justicia (Gaceta Oficial № 39.522 del $1^{\circ}$ de octubre de 2010), Reglamento Orgánico de la Escuela Nacional de la Magistratura (Gaceta Oficial 38192 del 23 Mayo 2005), Reglamento disciplinario Judicial; Decreto con Fuerza de Ley de Mensajes de Datos y Firmas Electrónicas (Gaceta Oficial № 37148 del 28 de febrero de 2001) y Decreto № 825 sobre Internet como prioridad (Gaceta Oficial № 36.955 del 22 de mayo de 2000).
} 
En este sentido, se describirán los procedimientos administrativos que se llevan a cabo en la ENM y se analizará cómo desarrollarlos por medios telemáticos, teniendo en cuenta que el logro de una reforma eficiente debe tener por objeto mejorar la relación Sociedad-Estado (AMOROSO, 2011,18), así como dinamizar y mejorar la calidad de los servicios que brinda el Estado (GUERRERO, 2011, 106).

\subsection{Procedimientos administrativos telemáticos.}

El acto y el procedimiento administrativos son válidos en formato electrónico como consecuencia del Decreto con Fuerza de Ley sobre Mensajes de Datos y Firmas Electrónicas ${ }^{5}$ (DLMDFE) (AMONI, 2010,150), ya que esta norma no solo se aplica en el ámbito del Derecho Privado sino también del Derecho Público y especialmente en el Derecho Administrativo, de modo pues que “... Los distintos entes públicos pueden, con base al DMDFE, entablar relaciones administrativas electrónicas con los particulares, así como emitir documentos electrónicos válidamente firmados, también de manera electrónica..." (ARCILA y DE LA BARRA, 2009).

Además, el principio de equivalencia funcional recogido en el DLMDFE, que sirve para reconocer la validez de talos actos en un entorno digital (GUTIÉRREZ, 2005, 13), ha permitido a la Administración Pública, cumplir, en formato electrónico, la actuaciones jurídicas que había venido realizando en formato papel.

Si aún tal reconocimiento expreso del uso de TIC por personas públicas, aunado a su equivalencia funcional respecto de los medios que existían antes de su introducción en la sociedad, no era suficiente para reconocer la validez de actos y procedimientos administrativos telemáticos en Venezuela, una norma legal previó de forma expresa que los órganos y entes del Estado podrían sustanciar sus actuaciones administrativas, total o parcialmente, por medios electrónicos: el artículo 49 de la LInf. (AMONI, 2016, 420).

A partir de entonces, con más razón, la falta de desarrollo pleno de procedimientos administrativos telemáticos no debía atender a dudas de quienes no estaban seguros de poder aplicar el DLMDFE en sede administrativa, sino que solo podía ser consecuencia de razones de carencia de equipamiento y programas informáticos, de “... digitalización de procedimientos administrativos (con los protocolos de seguridad respectivos)...”, de capacitación de los servidores públicos y de los ciudadanos (SIRA, 2015, 265), así como de voluntad, ya que no hacía falta otra norma que previera la migración hacia la telematización de la función administrativa, con independencia del órgano público de que se tratase.

En otras palabras, cada una de las fases del procedimiento administrativo se puede perfeccionar por medio de TIC aunque no exista un texto normativo que regule detalladamente el procedimiento administrativo telemático ni se haya modificado o derogado la LOPA por una norma de igual rango.

\footnotetext{
${ }^{5}$ Gaceta Oficial de la República Bolivariana de Venezuela nro. 37.076 del 13 de diciembre de 2000.
} 
No obstante, la falta de una ley orgánica especial que reforme o derogue y sustituya la Ley Orgánica de Procedimientos Administrativos ha llevado a parte de la doctrina venezolana a negarlo (HERNÁNDEZ, 2012, 46; BELANDRIA, 2017, 42; PELLEGRINO, 2014, 295 y ALFONSO, 2017, 56).

En ciertos casos se afirma que es de gran importancia reformar la Ley Orgánica de Procedimientos Administrativos para “...redimensionar la concepción tradicional del acto y el procedimiento administrativo..." (PELLEGRINO, 2014, 290) y así terminar con la ausencia de regulación, mediante un marco normativo que incluya el procedimiento administrativo electrónico (PELLEGRINO, 2014, 295), y que “... el procedimiento administrativo electrónico debe ser creado por Ley (con todas sus fases y etapas)..." (ALFONSO, 2017, 57).

No obstante, una revisión del DLMDFE permite concluir que cada uno de los requisitos de forma del acto y el procedimiento administrativos son válidamente ejecutables, en todas sus etapas, por medios electrónicos, salvo el sello húmedo, cuya ausencia ha sido reconocida como un vicio no invalidante por la jurisprudencia reiterada de la Sala Político Administrativa del Tribunal Supremo de Justicia (SPA) (AMONI, 2011, 87) y que, adicionalmente, no debe exigirse en un entorno digital por ser incompatible con el formato electrónico del acto administrativo telemático conforme al artículo 49 del DLI que prevé: "Serán aplicables a los expedientes administrativos electrónicos, todas las normas sobre procedimiento administrativo, en la medida en que no sean incompatibles con la naturaleza del medio empleado".

En cuanto a la falta de sello húmedo, si para la SPA un acto administrativo en papel es válido sin este elemento, con más razón lo será uno electrónico, puesto que el DLI reconoce la validez de todo expediente administrativo electrónico que cumpla con las normas de procedimiento administrativo compatibles con el formato electrónico, y puesto que no es posible incorporar un sello húmedo en un archivo informático, entonces este requisito desaparece en el acto administrativo electrónico.En Venezuela no se ha derogado la LOPA ni previsto un procedimiento administrativo telemático especial, y aún así, la regulación jurídica sobre el uso de TIC en actos y procedimientos administrativos, como las previsiones de la LInf que tiene por objeto “... facilitar la relación entre el Poder y los administrados a través del uso adecuado de las tecnologías de información y la simplificación de trámites y procedimientos administrativos..." (SIRA, 2015, 268), es suficientemente abundante para concluir que es válido aplicar la LOPA adaptando los requisitos formales al formato digital como se explicará a continuación al responder a los argumentos de quienes afirman que el procedimiento administrativo telemático requiere de una nueva ley.

Por una parte, se ha afirmado que los particulares ostentan el derecho a comunicarse con la Administración Pública por medios electrónicos, de acuerdo con la LInf, y que “... No obstante, al tratarse del análisis y posible reforma o la redacción de una nueva Ley Orgánica de Procedimientos Administrativos puede establecerse 
el derecho de los particulares a comunicarse por vía electrónica..." (ALFONSO, 2017, 64).

En este misma línea argumentativa, se ha afirmado que el procedimiento administrativo telemático no es válido con base en la normativa de derecho actual, pero sí lo es el expediente administrativo electrónico, la firma electrónica, la digitalización de archivos, el derecho a dirigir peticiones electrónicas, recibir notificaciones electrónicas y acceder electrónicamente a los expedientes, con la condición de que no contradigan lo dispuesto en la Constitución y en la legislación administrativa, como la LOPA y el Decreto con Rango, Valor y Fuerza de Ley Orgánica de la Administración Pública (BELANDRIA, 2017, 42).

A tales aseveraciones se opone lo siguiente:

1. La Constitución garantiza redes de informática con el fin de permitir el acceso universal a la información y promueve el estudio de las nuevas tecnologías en los centros educativos; si a esto se le suma que la Administración está al servicio de los particulares, y que la Constitución debe ser aplicada por todos sin que pueda ser inutilizada ante la falta de normas de rango legal que desarrollen los derechos que ella garantiza, el uso de las TIC en la actividad formal de la Administración Pública encuentra respaldo constitucional.

2. Si el procedimiento administrativo se constituye de una serie de actos por los que se forma la voluntad administrativa, que se documenta en un expediente administrativo, en este caso telemático; en el que constarán las peticiones y respuestas, telemáticas, entre la Administración y cualquier interesado; así como las notificaciones, también telemáticas, que se practiquen; al cual se puede acceder por medios telemáticos; puede entenderse que el procedimiento administrativo telemático resulta tan válido como la suma de tales partes, reconocidas como ajustadas a derecho por quienes estiman que estas sí lo son pero no el procedimiento conformado, justamente, por tales partes.

Y es que el procedimiento administrativo no pierde las conquistas democráticas alcanzadas por ser telemático, ya que así como sucede con su versión en papel, no está conformado por cualquier serie de actos, sino que estos deben: 1 . servir de garantía al derecho a la defensa, 2. permitir su control administrativo y judicial, previendo, por ejemplo, el deber de motivar los actos administrativos; y, 3. posibilitar la participación, bien sea mediante la intervención en audiencias o consultas públicas, según el caso, siempre que ello sea de interés general (SOUZA, 2016, 60).

3. En cuanto al argumento de que el procedimiento administrativo telemático será válido cuando "... así esté previsto en la ley, concretamente en la ley nacional..." (BELANDRIA, 2017, 43); o que se necesita “... la urgente reforma de la actual Ley Orgánica de Procedimientos Administrativos...” (PELLEGRINO, 2014, 295), desde 2001 el DLMDFE prevé en el artículo 1 que su objeto es “... otorgar y reconocer efi- 
cacia y valor jurídico a la Firma Electrónica, al Mensaje de Datos y a toda información inteligible en formato electrónico, independientemente de su soporte material, atribuible a personas naturales o jurídicas, públicas..." donde quedan incluidos los entes administrativos y en consecuencia, sus órganos.

Pero si esto no fuera suficiente, además, resultan aplicables el DLSTA, el DLAP, el DLI y la LInf, todas de rango legal y que reconocen que cada uno de los requisitos de forma del procedimiento administrativo pueden cumplirse por medios telemáticos, aunque no regulen un nuevo procedimiento administrativo.

Negar el cumplimiento de los requisitos formales de la LOPA mediante el DLMDFE, implica excluir la actividad administrativa de la equivalencia funcional que promueve este último texto normativo, y en consecuencia que los mensajes de datos de la Administración, con firma digital o electrónica certificada, no tienen valor alguno por no estar escritos en papel y con firma manuscrita, aunque la LInf prevé el uso de este tipo de firma para los funcionarios públicos al emitir actos en formato electrónico.

Es decir, se está totalmente de acuerdo con que sería mejor una reforma de la LOPA o su sustitución por una nueva ley, previa derogación por ley orgánica, de este texto legal, pero con lo que no se puede estar de acuerdo es con negar que puedan reconocerse nuevas y más amplias libertades personales, por actos de rango legal ordinario, porque el contenido de una ley orgánica determinada no lo haya previsto.

No se trata de defender que la LOPA fue modificada, sino que su regulación fue ampliada para cubrir las experiencias en el ámbito de la Administración Pública Telemática que han venido produciéndose en la práctica administrativa venezolana (AMONI, 2011 y SIRA, 2015, 294), la cual, necesariamente tenía que producirse por exigencias sociales, y que no puede quedar al arbitrio de la Administración sino que debe someterse al derecho administrativo, aplicando la legislación orgánica en armonía con las previsiones de rango legal ordinario, puesto que en la “...'digitalización de procedimientos administrativos'... se deben brindar al interesado las mismas garantías de un procedimiento tradicional" (SIRA, 2015, 296), lo que se obtiene de aplicar la LOPA junto al resto de la legislación, anteriormente enumerada.

Otro argumento que se utiliza para negar el acto y el procedimiento administrativos electrónicos es que estos solo se pueden escribir en papel, pero no manteniéndolos y compartiéndolos en una computadora o dispositivo de almacenamiento digital, ya que el principio de la escritura de la LOPA no incluye estas modalidades (HERNÁNDEZ, 223).

Tal posición rechaza tácitamente la interpretación histórico-progresiva, válida en la hermenéutica jurídica, ya que estima que la única escritura válida requiere papel y tinta cuando el medio común de escritura supone el uso de un teléfono celular, 
preferiblemete inteligente, o una computadora, sin necesidad de imprimir tales representaciones gráficas de las palabras (AMONI, 2010, 65), porque lo que se cambia es el soporte pero el acto se mantiene siendo escrito (PELLEGRINO, 2014, 293).

Es escrita la representación manual de palabras en un papel, así como lo fue su representación mediante máquinas de escribir y lo es, con celulares, vía mensaje de texto, y con teléfonos inteligentes, tabletas o computadoras, mediante mensajes de datos. En todo caso, como se expresó antes, lo que se hace es “... desplazar al papel como portador documental por excelencia" (VELANDIA, 2015,68), de ahí que el artículo 4 del DLMDFE admita la prueba escrita mediante mensajes de datos (VELANDIA, 2015, 91)

También se ha asegurado que la Sala Político-Administrativa, mediante la sentencia número 1.801 del 15 de diciembre de 2011 niega todo valor al acto administrativo electrónico (HERNÁNDEZ, 2012, 223); y aunque ello fue así, en realidad el problema radicaba en si el acto administrativo electrónico debía ser motivado, que en conclusión de la Sala no debía serlo, ya que el verdadero acto estaba en papel en el expediente administrativo y si quería conocerse debía solicitarse de nuevo, pero esta vez, que se lo emitieran en papel, tal como lo había expuesto en decisiones anteriores (AMONI, 2011, 59).

Sin embargo, cuando la entonces Comisión Nacional de Administración de Divisas (CADIVI) comenzó a incluir copia íntegra del acto administrativo en sus notificaciones, la falta de motivación, que era el problema reiterado, se solventó, admitiéndose la impugnación directamente contra el acto notificado por medios telemáticos sin que fuera necesario pedir el acto en papel para impugnarlo, como se advierte en el auto de la SPA número 93 del $1^{\circ}$ de agosto de 2017 y en la sentencia número 294 del 6 de abril de 2017.

En esta última decisión judicial se observa también el criterio de la Corte Primera de lo Contencioso Administrativo, cuya sentencia conocía la SPA en consulta, sobre el acto y procedimiento administrativo telemático en los términos siguientes:

“... debe esta Corte advertir que aún cuando los avances tecnológicos y la necesidad de simplificación de trámites administrativos impongan a los órganos y entes de la administración pública el deber de migrar a sistemas más eficientes y progresistas en aras de optimizar el ejercicio de la función pública, facilitando en lo posible el ejercicio de trámites tanto para los particulares o administrados como para la administración; no pueden omitirse los elementos formales establecidos en la normativa vigente, relativos a la eficacia de los actos administrativos, toda vez que los mismos son indispensables para que puedan surtir efectos jurídicos contra terceros. En este sentido, se exhorta a la Comisión de Administración de Divisas (CADIVI), a los fines que desarrolle un sistema más ajustado a la normativa vigente, especialmente en sintonía con la Ley de Procedi- 
mientos Administrativos, la Ley de Simplificación de Trámites Administrativos y el Decreto con Fuerza de Ley Sobre Mensajes de Datos y Firmas Electrónicas".

En este fallo, la Corte Primera de lo Contencioso Administrativo reconoce que el procedimiento administrativo telemático surge de una combinación normativa que incluye, al menos, la LOPA y el DLMDFE, de forma que ante el argumento de desconocimiento jurisprudencial surgieron sentencias posteriores que cambiaron dicho criterio (sentencias números 1358 del 15 de octubre de 2014 y 420 del 22 de abril de 2015).

En efecto, la misma SPA expresó en la sentencia referida número 294 del 6 de abril de 2017 que:

“... la demandante debía adecuarse a los mecanismos tecnológicos implementados por el órgano accionado para la época de los hechos (esto es, el Sistema Automatizado de la Comisión de Administración de Divisas (CADIVI), bien fuere a través de su página web www.cadivi.gob.ve, o mediante el correo electrónico indicado por la interesada, según corresponda) para realizar las gestiones relacionadas con sus solicitudes de autorización de adquisición de divisas, acceder a la información requerida, consultar su status, dirigir comunicaciones, recibir las notificaciones del resultado de dicho procedimiento administrativo, entre otros trámites"

La Sala reconoce que el procedimiento administrativo puede tramitarse íntegramente, desde el inicio hasta la notificación del acto administrativo, usando TIC, con lo que el argumento de negativa jurisprudencial queda superado, sin perjuicio de que pudiera cambiar asumiendo una posición contraria; aunque, se insiste, se está de acuerdo en que sería preferible una reforma o sustitución de la LOPA por otro texto legal que previera la modalidad telemática del procedimiento administrativo, pero preferible no es igual a indispensable, por lo que tanto procedimiento como el acto administrativos telemáticos, gozan de base legal en el país, lo que ha entendido la Administración al valerse de ello para el ejercicio de su actividad.

De los argumentos expuestos resulta que al inicio del procedimiento se ordena la apertura del expediente administrativo digital, mediante acto administrativo electrónico ${ }^{6}$ con firma electrónica certificada, el cual será archivado en un servidor informático de la institución. Luego, la notificación del servidor público, funcionario o trabajador, se puede practicar en la dirección de correo electrónico indicada al efecto, por el propio empleado, a la dirección de recursos humanos.

Posteriormente, la fase de sustanciación continúa con la respuesta que emitirá el notificado, bien sea mediante la dirección de correo electrónico suministrada para

\footnotetext{
${ }^{6}$ Se usa la denominación "Acto Administrativo Telemático" cuando se quiere hacer énfasis en la importancia que tiene poder acceder al mismo a distancia.
} 
intercambiar comunicaciones con la ENM o mediante papel firmado, el cual será escaneado, firmado con certificado electrónico y cargado al expediente administrativo digital archivando el original en cuaderno separado de lo cual se dejará constancia.

Las pruebas digitales se incorporarán al expediente en igual formato, mientras que las producidas bajo la modalidad tangible, serán incorporadas como se explicó antes.

La terminación del procedimiento, con el acto administrativo definitivo, también es verificable mediante el mensaje de datos y la firma electrónica certificada, con lo que se cumplen todos los requisitos formales: escritura (digital) y autenticidad (firma electrónica certificada siendo innecesario el sello).

Para finalizar, el acto será eficaz una vez notificado al interesado en la dirección de correo electrónico indicada para ello a la dirección de recursos humanos.

\subsection{El expediente administrativo digital}

La actividad administrativa se documenta mediante actos administrativos de trámite y definitivos con los que se conforman expedientes administrativos ${ }^{7}$, los cuales serán únicos, aunque intervengan varios órganos o entes ${ }^{8}$, y uniformes ${ }^{9}$, cuya versión digital encuentra reconocimiento expreso en el ordenamiento jurídico venezolano ${ }^{10}$ y que se muestra como una evolución natural en toda democracia, que va desde una Administración que actúa en papel, mediante expedientes en este formato, luego electrónica, vale decir, con expedientes electrónicos, para terminar en una administración abierta (GILLES, 2017, 71).

Esta transformación no solo requiere del Derecho Informático sino de la Informática Jurídica, entendida como el apoyo que ofrece la informática para diseñar medios que permitan cumplir con el ordenamiento de derecho (FLORES, 2009, 47). Se refiere al aspecto técnico informático necesario para poner en práctica los postulados de la norma jurídica informática.

Al tratarse de mensajes de datos firmados y organizados cronológicamente ${ }^{11}$, el expediente administrativo digital resulta posible con la firma electrónica certificada y con un programa informático adecuado para permitir una gestión plena del procedimiento $^{12}$, en todas sus fases: inicio, sustanciación, terminación y eficacia, con la

\footnotetext{
${ }^{7}$ Artículo 51 LOPA.

${ }^{8}$ Artículo 31 LOPA.

${ }^{9}$ Artículo 32 LOPA.

${ }^{10}$ Artículo 152,164 y 165 DLOAP y artículos 8 y 32 LInf.

${ }^{11}$ Artículo 164 y 165 DLOAP.

12 Sobre el tema del expediente electrónico, pero en sede judicial: Francisco González, Campo. “Configuración procesal del expediente judicial electrónico: hacia un derecho procesal electrónico"; Fodertics, estudios sobre Derecho y Nuevas Tecnologías; andavira, España, 2012, p. 206.
} 
eventual tramitación en segundo grado mediante los recursos administrativos y hasta su envío a los órganos jurisdiccionales para el control de la actividad administrativa.

No obstante, si no se cuenta con dicha tecnología ${ }^{13}$ deben buscarse soluciones para poder avanzar hacia su implementación, teniendo presente que algunos de los problemas del expediente administrativo en papel como "... el deficiente tratamiento documental en las Administraciones Públicas y la inexistente concepción de los archivos como parte integrante de la gestión administrativa..." (LLAMAS, 2012, 45) se reproducirán en la versión electrónica, a lo que debe sumarse la fragilidad y volatilidad de los datos electrónicos, los cuales pueden ser borrados o modificados sin dejar rastro (CANO, 2005, 200) o siendo difícil recuperarlos.

En este sentido, a fin de incorporar medidas de seguridad, además de la firma electrónica, si ella no lo proporcionara, sería útil usar un servicio de sellado de tiempo que permitiera garantizar que el orden de los documentos insertados ${ }^{14}$ no va a cambiar luego de haberlo introducido, exigencia que tampoco puede cumplirse cabalmente en formato papel, lo cual, no sería un obstáculo para la migración a un entorno digital.

Si la fecha y hora asociada a la firma electrónica certificada que se use no está relacionada con la fecha y hora de un servidor ajeno al control de la ENM sino que está relacionado con la propia computadora, esta sería manipulable, surgiendo como opción, tener que pedir copia firmada digitalmente de cada documento, incluso por correo electrónico, y solo en este caso, se pudiera tener certeza de que al momento de recibirla, el expediente contenía solo, los documentos enviados.

La fecha de envío de un documento electrónico se determina por el momento en que entra en un sistema informático que no pueda ser alterado por su autor o por quien actúe en su nombre o bajo se dependencia (MORENO, 1999, 29).

De hecho una solución, que además dificulta la alteración de datos electrónicos, pudiera consistir en enviarle al interesado un ejemplar del expediente digital, por correo electrónico, cada vez que se agregue un documento, a fin de dejar constancia, en un servidor informático ajeno al control de la ENM, del estado progresivo del expediente, salvo en los casos de documentos calificados como confidenciales ${ }^{15}$ que deberán archivarse en cuerpos separados del expediente y cuya consulta, en caso de afectar derechos del interesado, deberá hacerse en la oficina y no a distancia para garantizar la confidencialidad.

\footnotetext{
${ }^{13}$ Que debe ser en software libre conforme al artículo 35 del DLI.

14 Artículo 34 LOPA: "En el despacho de todos los asuntos se respetará rigurosamente el orden en que estos fueron presentados...".

${ }^{15}$ Artículo 59 LOPA.
} 
No obstante, esto no generaría un problema que obstaculizara la implementación del expediente administrativo digital ya que la misma posibilidad de alteración ocurre con el expediente administrativo en papel, siendo que solo la entrega de copias certificadas al interesado garantizaría que el expediente no fuera alterado o que en caso de serlo, se podría demostrar tal situación irregular.

Así mismo, la computación forense ofrece herramientas para detectar imprecisiones y dudas sobre la cadena de custodia de la evidencia digital que pudiera aportarse en caso de un eventual proceso jurisdiccional (CANO, 2005, 202) instaurado a fin de controlar la actividad administrativa telemática de la ENM.

Otro aspecto que debe tenerse en cuenta, si se pretende emular el expediente en papel en un entorno virtual es la posibilidad de enumerar las páginas del archivo para garantizar el orden de las piezas; no obstante, usando firma digital y además con sellado de tiempo o enviando el archivo por correo electrónico, parece que sería innecesaria la enumeración.

Sobre este tópico es importante recordar que la enumeración también ejerce un papel importante en la búsqueda de información dentro del expediente, lo que en el ámbito telemático resulta dispensable debido a la existencia de buscadores de palabras en un texto que permiten ubicar, en segundos, cualquier expresión.

Un elemento insoslayable es la interoperablidad ${ }^{16}$, cualidad que permite que los datos de autoría y documentos de acceso público que posean los expedientes de los órganos y entes del Estado, sean accesibles, intercambiables, transferibles y reutilizables por medios electrónicos, tanto entre administraciones públicas como entre estas y los tribunales para evitar que los adelantos en materia tecnológica se vean mermados por incompatibilidad entre órganos administrativos. Debe pensarse en rebasar las fronteras nacionales teniendo en cuenta las posibilidades de colaboración, en principio iberoamericanas (GUERRERO, 2011, 111), lo que se facilita por razones del idioma, y luego, internacionales en general.

También hay tener en cuenta el espacio de almacenamiento, aunque en el ámbito electrónico es mayor tal capacidad (LLAMAS, 2012, 46), en menos metros cúbicos. No deben perderse de vista los costos que implica adquirir, mantener y actualizar servidores informáticos, en los que se almacenarán los archivos digitales; así como los costos asociados a las condiciones atmosféricas, sistemas de seguridad tangibles e informáticos, y ubicación del servidor principal así como de los servidores informáticos de respaldo.

Una solución que viene aparejada a esta situación es la destrucción del archivo físico para liberar espacio, lo cual se concluye, por interpretación en contrario del artículo 153 LOAP: "Los documentos que posean valor histórico no podrán ser destruidos, aun cuando hayan sido reproducidos o almacenados mediante cualquier me-

\footnotetext{
${ }^{16}$ Artículo 22 del DLI y numeral 11 del artículo 5 de la LInf.
} 
dio", de modo que aquellos que no posean valor histórico, pareciera que sí pudieran serlo, en especial, una vez digitalizados.

En el entorno digital pudiera suceder lo mismo, ya que las comunicaciones, documentos y actuaciones electrónicas que realice el Poder Público se conservarán en las condiciones previstas en el ordenamiento jurídico ${ }^{17}$, previéndose la incorporación de tales mensajes de datos en repositorios digitales ${ }^{18}$.

Un elemento importante es la conservación de metadatos con la finalidad de identificar, verificar la autenticidad, mantener la integridad, buscar y recuperar los datos, sobre todo, en ambientes tecnológicos presumiblemente diversos del original (NERI, 2017, 35).

En todo caso, lo que se plantea es la modernización de la ENM y no una reforma, lo que requiere menor grado de complejidad ya que en lugar de una intensa y enérgica intervención en las estructuras y modo de funcionamiento, basta con un proceso de ajuste permanente y adaptaciones de la organización y sus funciones a los nuevos tiempos (MELO y OLIVEIRA, 2018, 105).

\subsection{El punto de cuenta.}

Antes de iniciar el análisis de los procedimientos particulares, es importante iniciar explicando cómo actúa la ENM. Al igual que sucede con otros órganos públicos

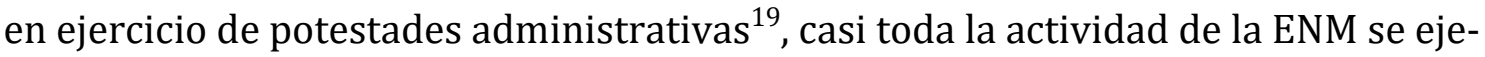
cuta previa emisión de puntos de cuenta. Se trata de un instrumento que no está

\footnotetext{
${ }^{17}$ Artículo 10 LInf.

${ }^{18}$ Artículo 11 LInf.

19 La Contraloría General de la República emitió el “...Punto de Cuenta de fecha 3 de febrero de 2000, aprobado por el Contralor General de la República, mediante el cual se determinó el régimen aplicable a los funcionarios adscritos a dicho órgano que fueran designados como Contralores estadales en virtud de la intervención que sufrieran posteriormente los órganos contralores regionales" (Sentencia de la Sala Político-Administrativa -SSPA- nro. 2387 del $1^{\circ}$ de noviembre de 2006); El Ministro del Poder Popular para la Economía Popular autorizó el "... Proyecto Casa Zamorana del Desarrollo Social..." mediante el “... Punto de Cuenta № SGCL-2007, de fecha 19 de septiembre del 2007 y Acto Motivado de fecha 20 de septiembre del 2007...", aprobado por el Ministro, para la construcción de 6 viviendas e igualmente, generó el “... Punto de Cuenta No VCMP-73 del 05 de agosto de 2008, mediante el cual el Ministro ...aprobó (...) proceder a la rescisión del mencionado contrato ..." (SSPA nro. 1218 del $1^{\circ}$ de diciembre de 2010); El Ministerio del Poder Popular del Despacho de la Presidencia presentó al Presidente de la República "...la propuesta de Reubicación de las Reservas Internacionales de la República en países aliados..." mediante “...Punto de Cuenta N $142-11 . . . "$ (Sentencia de la Sala Constitucional -SSC- nro. 1829 del $1^{\circ}$ de diciembre de 2011); La Fundación Fondo Nacional de Transporte Urbano (FONTUR) produjo el “... Punto de Cuenta Nro. 11 del 14 de febrero de 2006 en el cual el Presidente Ejecutivo del ente contratante aprobó el inicio de un procedimiento administrativo al Consorcio Esfega-Conintur...", así mismo, el "... Punto de Cuenta del 20 de enero de 2005 sometido al Consejo Directivo de la Fundación a fin de delegar en el Presidente Ejecutivo la apertura de procedimientos administrativos" (SSPA nro. 887 del 3 de agosto de 2017).
} 
definido en las leyes venezolanas ${ }^{20}$; no obstante, se menciona en el numeral 7 del artículo 61 del Decreto con Rango, Valor y Fuerza de Ley de Simplificación de Trámites Administrativos de 2014 (DLSTA): "El Directorio del Instituto Nacional para la Gestión Eficiente de Trámites y Permisos (INGETYP), tiene las siguientes competencias:... 7. Conocer puntos de cuentas e informes periódicos de la ejecución y desarrollo de la política y plan nacional".

De la norma parcialmente transcrita se infiere que el punto de cuenta es un instrumento utilizado para pasar de la norma a la materialización de actividades, por lo que pudiera tratarse un acto administrativo definitivo en tanto que requisito previo a la actuación material administrativa que no pretenda incurrir en vía de hecho.

Sin embargo, para la Sala Constitucional del Tribunal Supremo de Justicia e igualmente para la Sala Político-Administrativa del Máximo Tribunal, se trata de un acto administrativo de trámite y por ello, constitutivo del procedimiento previo al acto administrativo definitivo ${ }^{21}$.

A fin de precisar qué es un punto de cuenta en la ENM, es menester verificar en cuáles casos se acude a este instrumento jurídico.

\subsubsection{El punto de cuenta en la práctica de la ENM.}

En la ENM, los directores someten a la consideración del director general, la solicitud de aprobación de actividades mediante puntos de cuenta. Con base en tales instrumentos, el director general aprobará o no el requerimiento, luego de verificar el cumplimiento de los requisitos de ley, así como teniendo en consideración su oportunidad y conveniencia.

\footnotetext{
${ }^{20}$ La Ley Orgánica de Procedimientos Administrativos de 1981 (LOPA) prevé que "Los actos administrativos tienen la siguiente jerarquía: decretos, resoluciones, órdenes, providencias y otras decisiones dictadas por órganos y autoridades administrativas" (artículo 14). Luego de definir los decretos (presidenciales) y resoluciones (ministeriales) establece que "Las decisiones de los órganos de la Administración Pública Nacional, cuando no les corresponda la forma de decreto o resolución, conforme a los artículos anteriores, tendrán la denominación de orden o providencia administrativa. También, en su caso, podrán adoptar las formas de instrucciones o circulares" (artículo 17). El Decreto con Rango, Valor y Fuerza de Ley Orgánica de la Administración Pública de 2014 (LOAP) prescribe los siguientes tipos de acto administrativo: "El acto contentivo de la delegación intersubjetiva, interorgánica, y de la encomienda..." (artículo 40), el acto de avocación (artículo 41), el acto de constitución de las fundaciones públicas (artículo 110) y el acto de intervención de entes descentralizados (artículos 126 y 127).

${ }^{21}$ Para la Sala Constitucional, “... el término 'Punto de Cuenta' responde a la noción de acto administrativo de trámite -entendido este como todo acto preparatorio del acto administrativo final-, a través del cual un órgano de inferior jerarquía presenta una proposición a la consideración de un órgano superior dentro de la Administración Pública, de modo que es el acto emanado de la máxima autoridad, el acto administrativo firme que pudiera ser objeto de impugnación" (SSC nro. 1829 del $1^{\circ}$ de diciembre de 2011). Por su parte, la Sala Político Administrativa considera que "...el mencionado 'Punto de Cuenta' al que hace alusión el apoderado actor, no constituye más que un trámite administrativo que representa tan sólo una formalidad de la Administración para someter a la consideración de sus autoridades determinados asuntos, sin que su contenido sea influyente para modificar la Resolución impugnada" (SSPA nro.1218 del $1^{\circ}$ de diciembre de 2011).
} 
El punto de cuenta se usa, desde cada dirección, para solicitar el inicio de las actividades previstas en el Programa Operativo Anual (POA) del año en curso cuya ejecución progresiva se verifica mediante autorizaciones parciales o bien para autorizar actuaciones propias del funcionamiento de la institución, como la celebración de contratos y movimientos en la nómina de servidores (funcionarios y trabajadores). En caso de modificación o supresión, parcial o total, del punto de cuenta original, la dirección competente presentará un nuevo punto de cuenta.

A modo de ejemplo, la Dirección Docente tiene por práctica tramitar mediante puntos de cuenta la autorización para iniciar actividades de formación y capacitación (foros, congresos, diplomados, talleres y cursos en general). Aunque no siempre implican la generación de pagos, se trata de acciones cuya materialización requiere la intervención del talento humano y de los recursos existentes en la ENM, tales como su infraestructura (salones, auditorio, baños), vehículos oficiales (Ej. para trasladar docentes), mobiliario, equipos informáticos (video beam y computadora) así como bienes consumibles (Ej. papel, tóner para las impresiones y grapas).

Luego del punto de cuenta que autoriza el inicio de las actividades, se emiten tantos puntos de cuenta como: 1 . Ejecuciones presupuestarias se necesiten: pago de docentes, de expertos para construir los programas de estudio, gastos de refrigerios y viáticos; o 2. Modificaciones o supresión del punto de cuenta original sean necesarias.

Lo mismo ocurre en las demás direcciones: Carrera Judicial, Información y Documentación, Cooperación Técnica y Secretaría.

Mención aparte merece la Dirección de Administración y Recursos Humanos cuyos puntos de cuentan están referidos, principalmente, a contrataciones públicas, traspasos presupuestarios y movimientos de nómina, como sucede, por ejemplo, con la reparación de vehículos, compra de bienes y con el ingreso y ascenso de los servidores de la ENM.

Este acto jurídico se emite en papel, lo firman y sellan los directores relacionados con la actividad a ejecutar, e incluso, en ciertos casos interviene otro órgano público: la Dirección Ejecutiva de la Magistratura. Con él, se crea un expediente administrativo el cual se almacenará en un archivo tangible.

El último párrafo concentra los elementos que deben tenerse presentes para migrar del papel y la tinta a las TIC.

\subsubsection{El punto de cuenta digital.}

Como todo acto administrativo, de trámite o definitivo, el punto de cuenta debe constar por escrito (MORENO, 1999, 99) a fin de almacenarlo y transmitirlo, debe tener un número correlativo y debe ser auténtico, todo lo cual es jurídicamente posible usando TIC. 
En la ENM, el punto de cuenta puede ser redactado, en un procesador de palabras, por cualquier Dirección que requiera proponer la ejecución de una actividad a la Dirección General. Será enviado a la unidad de asesoría jurídica para su revisión, quien en caso de no tener objeciones, lo regresará a la Dirección proponente para su transformación en un formato no modificable, como PDF, el cual se enumerará y firmará digitalmente por el director correspondiente.

Con ese archivo se formará un expediente digital que contendrá los demás documentos pertinentes.

Al tratarse de documentos, o actos que constan en un instrumento para representar algo (VELANDIA, 2015, 66), es posible migrar al punto de cuenta digital puesto que se trata de mensajes de datos con firma electrónica certificada, instrumentos jurídicamente válidos en Venezuela desde $2002^{22}$ y en el caso de la firma, disponible en el país desde 2008.

Es decir, el punto de cuenta se emitiría mediante un texto recolectable y reproducible de modo inteligible, mediante un procedimiento tecnológico confiable (VELANDIA, 2015, 145)

Este tendría firma electrónica certificada o digital, que es el tipo de firma electrónica conformada por un sistema de criptografía asimétrico o de clave pública generada por un tercero de confianza (ZUBIETA, 2005, 75) que garantiza la confidencialidad e integridad del mensaje de datos, de consuno con la identidad de las partes en comunicación (VELANDIA, 2015, 255).

\subsubsection{Naturaleza jurídica del punto de cuenta en la ENM.}

Visto que la ENM utiliza el punto de cuenta para que el director general autorice la ejecución de actividades inherentes al cumplimiento de las responsabilidades institucionales, este funcionará en ocasiones como acto administrativo de trámite, como sucede cuando se autoriza el inicio de un programa académico, o como acto administrativo definitivo cuando se aprueba y en consecuencia se ordena el pago de un docente o incluso, cuando este se negare.

Ese acto resulta válido en formato electrónico porque el ordenamiento jurídico patrio lo reconoce expresamente en el DLMDFE, DLST, LI y en la LInf., incluso, el Consejo Directivo de la ENM, mediante acta de consejo directivo $\mathrm{N}^{\circ} 17$ del 6 de noviembre de 2018 aprobó la tramitación del punto de cuenta electrónico mediante la cual se regula la elaboración, transmisión y archivo del punto de cuenta en dicho formato.

No obstante, hay una excepción: cuando la información deba enviarse a otro ente u órgano, para completar determinado procedimiento, y este no haya incorporado

${ }^{22}$ Con la entrada en vigencia del DLMDFE. 
aún a su actividad el uso de la firma electrónica certificada y del expediente administrativo electrónico.

Aquí el obstáculo no es jurídico sino de “...alfabetización tecnológica, equipamiento computacional, software, grado de capacitación y estilo de gestión" (HUSSMANN, $2004,15)$, donde la decisión de las máximas autoridades es fundamental para su puesta en marcha, y luego, el compromiso de las autoridades intermedias involucradas será determinante para promover e instituir su práctica entre todos los servidores públicos.

\section{Los procedimientos administrativos en las diversas unidades admi- nistrativas de la ENM.}

\subsection{Dirección de Docencia}

\subsubsection{Actividades académicas}

\subsubsection{Foros y congresos}

Una de las actividades recurrentes de la ENM son los foros, oportunidad para el debate e intercambio de experiencias entre servidores judiciales, localizados en el mismo auditorio o interconectados mediante videoconferencia.

Dado que el sistema informático actual (2019) de la ENM permite realizar videoconferencias con cuatro estados en simultáneo, se aprovecha esta tecnología para cumplir con el deber de formar y capacitar a los servidores judiciales, sin que se deba incurrir en gastos de transporte, alojamiento y alimentación, optimizando el uso de los recursos para atender a más personas, sin importar dónde se encontraren.

Este ahorro de recursos no es solo institucional sino que especialmente se facilita el acceso (RICO, 2011, 219) a la educación de quienes se encuentran alejados de su centro de formación y capacitación oficial, ubicado, hasta el momento en que se actualizaron estas líneas (enero de 2020), solamente en la ciudad de Caracas.

De tal manera, se actúa en consonancia con el artículo 141 constitucional en virtud del cual la Administración está al servicio de los particulares, quienes merecen el mayor esfuerzo por parte del Estado para cumplir su misión del modo más idóneo posible para el beneficiario, aunque no siempre el resultado sea exitoso por problemas en el servicio eléctrico o en el servicio de Internet en el interior del país, o como consecuencia de la no poco conocida "caída del sistema", lo que requiere mayor inversión puesto que en un Estado Constitucional, tal explicación como justificación para la vulneración de derechos deja de ser aceptable (REYES, 2011, 203).

Además de la actividad central como es el desarrollo de las ponencias, y el ciclo de preguntas y respuestas, todos ejecutados por videoconferencia, y posteriormente 
puestos a disposición del público mediante el canal de Youtube de la ENM, el registro de los participantes y la certificación, se realizan igualmente por medios digitales.

En el primer caso, los asistentes presentan sus datos a los servidores de la ENM, quienes los ingresarán en sus computadoras manualmente, para elaborar luego los certificados de asistencia que son autenticados con firma digital o electrónica certificada, por la Secretaria General y el Director General. Tales certificados son enviados por correo electrónico y/o cargados en el portal de Internet oficial para que los interesados los descarguen.

En caso de que alguna persona requiera su certificado en papel, podrá imprimirlo en el papel de su preferencia y llevarlo hasta las oficinas de la ENM para ser firmado y sellado por las referidas autoridades.

Con ello se ofrece la opción de acceder a su certificado a quien no tenga Internet ni computadora o teléfono inteligente. Y es que no basta la sola existencia de la tecnología necesaria para interactuar a distancia sino, además, que esté disponible (NAHABETIÁN, 2011, 146) y en tercer lugar, que la persona que pueda interactuar a distancia se preocupe por hacerlo o se sienta cómoda haciéndolo (LIMBERGER y LOPES, 2011, 120).

\subsubsection{Diplomados}

En la ENM, los programas de formación y capacitación se desarrollan mediante cursos especializados que en su conjunto, de ser aprobados, dan lugar a una certificación con la categoría de diplomado.

Las clases, tradicionalmente han sido presenciales pero ya se ha iniciado la migración paulatina a plataformas digitales bajo la modalidad de "Aula Virtual", gracias a las cuales, docentes y estudiantes no requerirán desplazarse hasta el aula de clases, ni realizar exámenes o documentar investigaciones en papel, sino que todo ello podrá verificarse a distancia, con ahorro de tiempo para ambas partes.

En lo que concierne a los aspectos administrativos, la convocatoria, inscripción, listas de asistencia, evaluaciones y consignación de notas, aunque parcialmente se realizan en formato papel, son materializables mediante TIC.

La convocatoria así como la inscripción, y algunas evaluaciones, son realizadas de modo electrónico, mientras que las listas de asistencia, ciertas evaluaciones y la consignación de notas, se verifican en formato tangible, específicamente, en papel.

No obstante, el proceso pudiera ser enteramente digital si todos los alumnos y profesores utilizaren firma electrónica certificada; sin embargo, el DLMFE, permite más opciones. 
Respecto de la convocatoria, se realiza por las redes sociales oficiales, así como por correo electrónico enviado a jueces rectores, presidentes de circuito, coordinadores jurisdiccionales y magistrados del Tribunal Supremo de Justicia, mediante invitación con firma electrónica certificada. Las referidas autoridades judiciales remiten, por la misma vía, la lista de postulados para inscribirlos digitalmente, sin que sea necesario formalizar una inscripción en papel.

En el caso de las listas de asistencia, en ausencia de un programa informático con captahuellas u otro sistema biométrico de identificación, sería suficiente fotografiar al alumno, mostrando su cédula de identidad, indicando en la pizarra acrílica del aula o en algún otro soporte, como la pantalla de una computadora, el lugar, fecha y materia a cursar para crear, luego, un solo archivo con todas estas imágenes, que será firmado por un servidor de la ENM, a fin de dejar constancia de la fecha de la actividad, lo cual pudiera mejorarse con un programa de sellado de tiempo, excluyendo el uso de información escrita al lado del participante.

Las evaluaciones, incluso los tradicionales exámenes de desarrollo, selección simple o múltiple o completación, pueden realizarse en formato electrónico, e incluso, a distancia, por un programa especialmente diseñado al efecto o por correo electrónico.

La consignación de notas es otro trámite que pudiera practicarse perfectamente con firma electrónica certificada del profesor correspondiente, para ser incluida en el expediente administrativo digital; no obstante, usando la firma electrónica pactada (AMONI, 2013, 520), prevista en el artículo 16 del DLMDFE, las notas pueden enviarse por correo electrónico el cual se descarga, y se anexa al expediente junto a una copia escaneada del contrato por el que se acordó la modalidad de firma electrónica.

Incluso, pudiera mantenerse el acta de calificaciones en papel, escaneada y anexada al expediente digital, mencionando que el original se encuentra almacenado en físico en un cuaderno separado tangible, en los archivos en papel institucionales.

\subsection{Dirección de Administración y Recursos Humanos.}

\subsubsection{Contrataciones públicas o contrataciones del Estado ${ }^{23}$.}

La actividad mercantil se ha visto impregnada de TIC, en especial de actuaciones de los agentes económicos mediante Internet (CHACÓN, 2011, 35) lo que necesariamente migra a la actividad contractual estatal, puesto que el Estado interactúa económicamente con los particulares.

\footnotetext{
${ }^{23}$ La discusión sobre el contrato administrativo como categoría distinta al contrato privado ha llevado a usar expresiones genéricas como la de contratos públicos o del Estado (TORREALBA, 2012, 223-237 y HERNÁNDEZ, 2008, 380 RAP).
} 
Muestra de esto es el DLCP ${ }^{24}$ y su reglamento ${ }^{25}$ (RLCP), que prevén expresamente, el uso de TIC para las distintas modalidades de selección de contratistas como son: el concurso abierto, el concurso cerrado, la consulta de precios y la contratación directa. No es una obligación como en Perú, donde los proveedores deben licitar mediante TIC (SOTO y QUIÑÓNEZ, 2016, 141), sino de la posibilidad de ofrecer otra opción, además del uso del papel y la tinta, para celebrar contratos valiéndose del mensaje de datos y la firma electrónica.

Se trata de una contratación electrónica porque se usan medios electrónicos para formar la voluntad de las partes o para el desarrollo o interpretación del acuerdo (Flores, 2009, 119), pero pensar que la mera regulación es suficiente es un acto de ingenuidad. Establecer una política pública clara y de la que estén convencidos quienes la ejecutarán es indispensable para lograr su instauración con éxito. Debe entenderse, como parte de un plan de telematización del Estado, que en el caso concreto de las compras públicas, no basta con proveer TIC, sino que debe asegurarse su asimilación y uso en la cultura organizacional de la institución contratante (HUSSMANN, 2004, 30), en este caso, de la ENM.

Para tal fin, el pliego de condiciones deberá especificar los elementos tecnológicos, programas y demás requerimientos necesarios para participar en la respectiva modalidad de selección, lo cual será verificado y evaluado por el Servicio Nacional de Contrataciones, para garantizar el cumplimiento de los principios señalados en el DLCP y lo establecido en su reglamento ${ }^{26}$.

Entre esas condiciones pudiera plantearse el uso de "agentes electrónicos", que son programas informáticos incorporados al sistema de contratación por una persona para que responda o realice una acción, en su nombre, de forma automática y por tanto sin revisión humana previa (ARANGO, 2005, 59) o incluso de inteligencias artificiales.

Incluso, el Director General del Servicio Nacional de Contrataciones, emitió la providencia DG-2009-C-0020 ${ }^{27}$ mediante la cual se prevé: “... implementar la Tecnología de Firmas Electrónicas en el Registro Nacional de Contratistas...”.

Así mismo, la Ley Constitucional contra la Guerra Económica para la Racionalidad y Uniformidad en la Adquisición de Bienes, Servicios y Obras Públicas ${ }^{28}$, sin entrar a analizar su validez por su origen en la Asamblea Nacional Constituyente y no en la Asamblea Nacional, promueve el uso de las TIC en los procedimientos de contrataciones pública ${ }^{29}$, previendo el modo de incorporar documentos en papel al expe-

\footnotetext{
${ }^{24}$ Artículos 104 y 105.

${ }^{25}$ Reglamento de la Ley de Contrataciones Públicas, Gaceta Oficial nro 39.181 del 19 de mayo de 2009.

${ }^{26}$ Numeral 8 del artículo 54..

${ }^{27}$ Gaceta Oficial 39.337 del 30 de diciembre de 2009.

${ }^{28}$ Gaceta Oficial N 41.318 del 11 de enero de 2018.

${ }^{29}$ Artículo 12.
} 
diente administrativo digital ${ }^{30}$, lo cual, aunque ya estaba previsto en el DLI, es una reafirmación de la tendencia mundial a la telematización estatal, que contribuye a la implementación de procedimientos de contrataciones públicas telemáticas en el país.

Como ocurre con el DLMDFE, al cual hay que acudir para aplicar la LOPA, la LOAP, la LSTA, el DLI y la LInf., en la regulación de las contrataciones públicas mediante TIC no se detalla un procedimiento especial sino que debe analizarse cada uno de los procedimientos de contrataciones para precisar el cambio en sus aspectos formales, verificando antes las disposiciones que les son comunes.

Así, a pesar de la previsión genérica del DLCP sobre contrataciones públicas electrónicas y del artículo 120 del RLCP según el cual todas las formalidades o solemnidades podrán realizarse utilizando medios electrónicos, el referido instrumento sublegal prevé tres condiciones específicas:

La primera, es que deben usarse al menos tres programas informáticos para leer e intercambiar los mensajes de datos relativos a la contratación pública en proceso. Tales programas deben ser en software libre y estándares abiertos ${ }^{31}$, a pesar de las críticas que puedan presentarse, en especial, atinentes a la libertad de mercado y competencia (RÍOS, 2005, 521) garantizados constitucionalmente.

Fuero de los aspectos comerciales indicados, tal previsión responde al principio de neutralidad tecnológica con el que pretende evitarse la vinculación de la ley con determinada tecnología (GUTIÉRREZ, 2005, 14) y por tanto, la obstaculización en la formación de los contratos por la rápida obsolescencia legislativa (ARANGO, 2005, $65)$.

La segunda, impone que debe mantenerse la posibilidad de contratar por medios tradicionales, es decir, en papel con firma manuscrita y sello, trasladándose hasta el edificio donde se encuentra la ENM para intercambiar documentos, derecho que también está reconocido en el artículo 7 de la Ley de Infogobierno.

Y la tercera, "...el órgano o ente contratante debe garantizar la unidad del expediente mediante el establecimiento e integración de las piezas separadas cuando se utilicen medios electrónicos y tradicionales".

En toda contratación pública, los participantes deben estar inscritos en el Registro Nacional de Contratistas, lo que puede verificarse directamente en el Portal de Internet del referido órgano, siendo innecesario entregar la acreditación en papel.

Igualmente, es materia común al concurso abierto, cerrado y a la consulta de precios, la existencia de un pliego de condiciones que puede publicarse en el portal de Internet y en un enlace en las redes sociales de la ENM, dado que, atendiendo al

\footnotetext{
${ }^{30}$ Artículo 13.

${ }^{31}$ Artículo 34 de la Ley de Infogobierno y 35 del DLI.
} 
principio de publicidad, debe ofrecerse al público la mayor cantidad de información posible sobre la actuación administrativa y facilitar el acceso de todos los interesados a sus diferentes etapas (MELO y OLIVEIRA, 2018, 103). La puesta a disposición de estos datos en Internet no impide que se pueda cobrar por transferencia bancaria para obtenerlo, o mediante algún otro sistema seguro de pago a distan$\mathrm{cia}^{32}$, que es uno de los requisitos fundamentales del comercio electrónico (MORENO, 1999, 9) aplicable también a las contrataciones públicas.

En caso de concurso cerrado y consulta de precios, se enviará por correo electrónico junto a la invitación a participar, debiendo constar en el expediente de la contratación, constancia del envío y la recepción de las invitaciones remitidas ${ }^{33}$.

Ahora bien, en el caso de contratación directa, las condiciones serán preparadas por la ENM y se enviarán, igualmente, por correo electrónico, siendo anexadas al expediente administrativo digital.

El pliego de condiciones se conforma por un conjunto de documentos, algunos de los cuales deben ser cumplimentados y firmados por el participante. Si tiene firma electrónica certificada bastará su incorporación en el documento, de lo contrario, podrá enviarse en papel con firma manuscrita, y será escaneado, firmado digitalmente por el funcionario autorizado al efecto e incorporado al expediente administrativo digital, guardando los originales en un cuaderno separado en formato papel.

En caso de modificación del pliego de condiciones la ENM deberá notificar a los participantes, lo cual puede realizar mediante TIC.

Los participantes pueden pedir aclaratorias al pliego de condiciones, lo cual es factible por correo electrónico o en el portal de Internet de la ENM, tales aclaratorias se incluirán en el pliego de condiciones y de ellos se informará a los participantes, por cualquiera de las vías indicadas previamente.

Por su parte, la ENM también puede pedir a los oferentes la prórroga de sus ofertas, acto de comunicación administrativo que puede ejecutarse por correo electrónico o mediante un sistema creado especialmente al efecto.

También es posible emitir el acto motivado de ampliación de lapsos y términos en modalidades de contratación, en formato electrónico, pues se trata de un simple mensaje de datos con firma electrónica certificada de la máxima autoridad de la ENM.

\footnotetext{
32 Numeral 2 del artículo 8 del DLI.

33 Aunque el artículo 113 del RLCP solo prevé este deber para la consulta de precios ("Las invitaciones para participar en la modalidad de consulta de precios podrán ser efectuadas mediante remisión escrita a los participantes, por fax o por correo electrónico; en todos los casos el órgano o ente contratante deberá solicitar y mantener en el expediente de la contratación, constancia del envío y la recepción de las invitaciones remitidas"), este se extiende al concurso cerrado conforme al artículo 120 eiusdem.
} 
Otro aspecto que puede materializarse de modo electrónico es la celebración de contratos y adendas en los casos de adjudicación plurianual.

En resumen, visto que los requisitos no son más que documentos con firma manuscrita, pueden sustituirse perfectamente por mensajes de datos con firma electrónica certificada o en su defecto, mantenerlos en formato papel, debiendo escanearse y firmarse por el servidor de la ENM autorizado para tal fin.

\subsubsection{Concurso abierto.}

En el concurso abierto los oferentes presentarán sobres cerrados con la documentación correspondiente, en las tres modalidades de contratación abierta. Esto es posible en un entorno digital, enviando el mensaje encriptado, el cual será abierto solo con la clave que posea el oferente, y mediante un sistema informático que indique, sin que puedan borrarse los datos de acceso, cuándo se desencriptó la información; sin embargo, si se entiende que solo podrá realizarse en sobre en papel, desconociendo las previsiones legales expresas sobre digitalización de las contrataciones públicas, entonces pudiera enviarse en un disco compacto, blu-ray u otro medio de almacenamiento, dentro de un sobre cerrado, lo cual supondría desechar una de las ventajas de los mensajes de datos, como es su transmisión a distancia.

Así mismo, en los casos excepcionales de la publicación del llamado a participar en concursos abiertos, por medios de comunicación de circulación regional o local, nada obsta para que tales publicaciones sean en medios digitales.

\subsubsection{Concurso cerrado.}

En esta modalidad se hace referencia a sobres cerrados y a su entrega en acto público, a la redacción de actas y a la apertura de los sobres cerrados en acto público.

Tanto en lo relativo a los sobres cerrados como a las actas, resulta aplicable lo expresado hasta el momento en párrafos anteriores; es decir, que tanto el contenido de los sobres cerrados como el acta pudieran elaborarse mediante mensajes de datos con firma electrónica certificada, o en papel firmado manualmente que será digitalizado y firmado digitalmente por el servidor autorizado para ello, pudiendo mantener el original en un cuaderno separado.

Del mismo modo, el sobre sellado puede emularse con programas informáticos que permitan comprobar si la información encriptada fue revisada antes del concurso.

\subsubsection{Consulta de precios.}

Se requiere solicitar, al menos tres ofertas, pudiendo contratarse si se recibió una sola que cumpla con los requisitos de ley. El procedimiento incluye evaluar ofertas, emitir el informe de recomendación, adjudicación y notificación de los resultados. 
La solicitud de las ofertas puede ser por correo electrónico, bastando que la oferta sea recibida por el mismo medio, siendo innecesaria su presentación en papel; sin embargo, sería preferible, si el oferente no contara con firma electrónica certificada.

El informe y la adjudicación pueden generarse mediante mensajes de datos con firma electrónica y la notificación puede emitirse en el mismo formato.

\subsubsection{Contratación directa.}

Supone un auto motivado por el que se justifique este tipo de contratación; además, pudiera ser necesaria la declaratoria de emergencia comprobada, en cuyo caso, se deberá remitir al órgano de control interno, mensualmente, las decisión de contratación por emergencia comprobada anexando los actos motivados sobre esta modalidad de contratación pública.

Nuevamente, por tratarse de documentos firmados, pueden sustituirse por mensajes de datos con firmas electrónicas certificadas, incluso, si la comisión de contrataciones debiera intervenir, por lo que sus miembros deben contar con firma electrónica certificada.

\subsubsection{Permisos y vacaciones}

Del mismo modo que sucede con cualquier otra actividad que requiera documentarse, los permisos y vacaciones pueden requerirse y otorgarse, por mensajes de datos, con firma electrónica, así como almacenarse en expedientes administrativos digitales.

Una opción célere, ante la imposibilidad de dotar a cada servidor público de firma electrónica certificada, sería el uso de la firma electrónica pactada.

A través de la Dirección de Administración y Recursos Humanos de la ENM se distribuyó un documento en papel mediante el cual, cada servidor público declaraba la dirección de correo electrónico a utilizar para intercambiar comunicaciones con la institución, pactando que el modo de identificarse sería a través de dicha dirección postal telemática ${ }^{34}$. En consecuencia, los permisos y vacaciones pueden solicitarse y otorgarse, válidamente, usando TIC, siendo almacenados en expedientes administrativos digitales con firma certificada del director de recursos humanos o de algún funcionario autorizado a tal fin.

En todo caso, todos los directores de la ENM cuentan con firma electrónica certificada, por lo que la autorización se avalaría con la firma pactada del servidor pero con la firma electrónica certificada del director que lo autoriza o lo niega.

\subsubsection{Movimientos funcionariales y laborales.}

34 El artículo 6 de la LInf prevé el uso de TIC en su gestión interna y relaciones en general. 
El ingreso, egreso, ascenso, comisión de servicio, reubicación o cualquier otro cambio en la relación funcionarial o laboral de los servidores públicos de la ENM debe documentarse, y completar un proceso en el que intervienen tanto la institución como la Dirección Ejecutiva de la Magistratura.

Al tratarse de escritos firmados y sellados que deben ser archivados, todo el proceso es jurídicamente válido en un entorno digital, ya que justo esta es la idea en la que se sustenta el gobierno electrónico, facilitar la realización de actividades internas, como en este caso, o externas, en relación con los particulares, valiéndose de medios electrónicos para tal fin (SOUZA, 2016, 66).

En cuanto al ingreso de los servidores, tanto la convocatoria al concurso, la recepción de recaudos, como el concurso y sus resultados, pueden desarrollarse usando TIC, salvo aquellos casos en los cuales se considere necesario la presencia tangible de la persona concursante.

La convocatoria puede realizarse, y de hecho así ocurre, en el portal de Internet de la ENM y en sus redes sociales, lo cual, en caso disponibilidad presupuestaria, puede complementarse con publicaciones en periódicos digitales o en papel así como también, mediante anuncios en las universidades o centros de formación vinculados al área requerida.

La recepción de documentos, podrá hacerse en formato electrónico, salvo que se requiriera algún documento cuyo original estuviera en papel, en ese caso, deberá consignarse de tal modo, sin perjuicio de lo previsto en el DLI sobre intercambio de datos de autoría entre órganos y entes públicos.

Las pruebas, según su naturaleza, pudieran realizarse a distancia, tal como ha ocurrido mediante la respuesta a exámenes de desarrollo mediante correo electrónico, puesto que incluso, realizando la evaluación en la misma oficina de recursos humanos, se le permite a la persona concursante acceder a Internet, comunicarse con terceros y en general, valerse de todos los medios a los que tendría acceso en una situación real.

Hay actividades que requerirán la presencia tangible, como la entrevista, para observar su comportamiento antes, durante y después de esta fase, así como para observar su interacción con el entorno y con los demás trabajadores; no obstante, la entrevista pudiera efectuarse a distancia como sucedió en una ocasión, ya que la vista y el oído son los sentidos principales utilizados al momento de efectuarla.

Excepcionalmente pudiera usarse también el sentido del olfato y así detectar si la persona acude al lugar de trabajo en condiciones óptimas, y no, por ejemplo, con olor a bebidas alcohólicas. Por tanto, en caso efectuar la entrevista por medios telemáticos, el uso de los demás sentidos quedaría garantizado con la prueba in situ. 
Luego de la entrevista con la dirección de recursos humanos y con el supervisor inmediato, la ENM instauró como práctica, antes de ingresar a una persona, someterla a un día de prueba a fin de evaluar su capacidad de responder a las tareas asignadas, proactividad, responsabilidad en el cumplimiento del horario, así como el respeto a la autoridad y a los demás compañeros. De modo que esta sería la oportunidad de apreciar, con todos los sentidos, la efectividad de quien opta a ingresar a la ENM, eliminando las deficiencias que pudiera implicar la entrevista mediante TIC.

Todas estas fases se van documentando, lo que puede cumplirse con un mensaje de datos y firma electrónica, como se ha venido sosteniendo. El único obstáculo independiente de la institución sería la continuación del procedimiento ante la Dirección Ejecutiva de la Magistratura, en caso de no haber puesto en práctica el expediente administrativo digital o haberlo hecho obviando la interoperabilidad, entendida como la capacidad de los sistemas informáticos de compartir datos (GARCÍA, $2013,114)$.

Los mismos razonamientos aplican, mutatis mutandi, a las formas que deben cumplir los demás movimientos de personal enumerados al inicio de este epígrafe.

\subsubsection{Nómina}

El área de nómina se encarga de tramitar los pagos de los servidores judiciales y de los docentes y ponentes que participen en actividades académicas de la ENM. A su vez, solicita recursos presupuestarios, traspasos, cuota de compromiso y desembolso ante la Dirección Ejecutiva de la Magistratura, quien realiza el enlace ante la Oficina Nacional de Presupuesto (Onapre) para su aprobación y asignación, a fin de cumplir con los compromisos de pago adquiridos.

El procedimiento se realiza en papel, con firma manuscrita y sello de los servidores que se encargan de elaborar las planillas correspondientes, que deberán enviarse con un mensajero a la Dirección Ejecutiva de la Magistratura desde donde se ordenará el pago correspondiente.

En este caso se requiere del consenso de ambos órganos auxiliares del Tribunal Supremo de Justicia, así como de la Onapre, por ser un acto administrativo complejo, para poder materializarse por la vía telemática.

\subsection{Recursos documentales}

Además de la docencia, como toda academia, a la ENM le corresponde fomentar y generar la investigación.

La forma primigenia y natural de hacerla es a través de la revista científica, arbitrada e indizada, de la ENM: Magistra, que es una publicación anual sobre temas jurídicos que desde 2017 comenzó a publicarse en formato electrónico. Los servidores 
judiciales y en general, cualquier persona que desee publicar o leerla, podrá acceder a ella usando las TIC.

Así, la convocatoria para publicar en ella, el arbitraje de los artículos y la notificación de aceptación o negativa del artículo, luego de haber aprobado o no los dos arbitrajes favorables necesarios para tal fin, se realizan en un entorno digital.

El autor envía su colaboración por correo electrónico o la carga directamente en un enlace en Internet de la revista.

Una vez recibida, el director de la revista lo remitirá, por correo electrónico, a dos árbitros especialistas en la materia de que se trate, quienes presentarán el veredicto del mismo modo. La respuesta será notificada, igualmente por correo electrónico a los aspirantes a publicar en la revista Magistra.

\subsection{Secretaría}

En esta unidad administrativa destacan el área de "control de estudios" y de "evaluación, seguimiento y monitoreo de programas". La primera, es importante por encargarse de facilitar a los interesados sus constancias de notas, del historial de actividades en las que participó, programas culminados, iniciados y cantidad de pruebas superadas o no.

La entrega de los certificados, destaca como actividad recurrente. Por tratarse de documentos, se elaboran y envían mediante mensajes de datos a la dirección de correo electrónico indicada por el participante.

Otra opción utilizada ha sido cargarlos en el portal de Internet oficial de la ENM de modo que cada interesado lo descargue. Para acceder a ellos, durante la actividad académica correspondiente, se indica una clave a los asistentes quienes podrán descargarlos de forma restringida, a fin de evitar vulnerar derechos fundamentales por el tratamiento inadecuado de datos personales (REMOLINA, 2004, 118), es decir, en salvaguarda de los datos personales que por tal condición no son información pública (GARCÍA, 2011, 100) y que para fortalecerla se debe complementar solicitando autorización expresa y por escrito de la persona cuyo dato se haya requerido para incluirlo en la base de datos (REMOLINA, 2011, 129).

No obstante, se trata de soluciones temporales hasta que se obtenga el sistema de gestión documental, programa informático desarrollado para facilitar el manejo del área de control de estudios donde el estudiante pueda ingresar con un nombre de usuario y contraseña para descargar el documento académico requerido desde esta herramienta tecnológica.

Si la persona requirente deseare su constancia o certificación en papel u otro soporte tangible, puede imprimirla por cuenta propia, y hacerla llegar hasta la ENM, en Caracas, donde se le firmará y sellará. 
Adicionalmente, la Secretaría de la ENM evalúa las actividades académicas de la institución. Cuando lo hace en el edificio donde funciona la ENM, al finalizar cada actividad, una muestra de participantes es guiada hasta el laboratorio de computación donde los asistentes opinan y evalúan aspectos como la organización, el espacio, la atención, cumplimiento de objetivos, importancia de la actividad para el desempeño de sus actividades laborales y calidad de los ponentes.

Esta evaluación es digital, así como los resultados obtenidos. La notificación de los resultados también se envía al docente o ponente en ese formato, específicamente por correo electrónico, y en el mismo entorno digital, se distribuye, vía carpeta compartida, a las Direcciones vinculadas con la actividad a fin de tomar los correctivos pertinentes.

Con estas soluciones se evitan gastos de traslado, impresión y almacenamiento, generando celeridad y seguridad en el acceso a la función administrativa ejercida por órganos judiciales, como la Escuela Nacional de la Magistratura.

\subsection{Oficina de Cooperación Técnica}

Hay un área cuya función está ligada, plenamente, a las TIC. Se trata de la unidad de comunicación social. La persona encargada del área difundirá la noticia mediante las redes sociales de la ENM, captará las imágenes, las transmitirá, incluso desde el interior del país, redactara la nota prensa y las publicará en un entorno netamente digital.

Si bien no se trata de actos jurídicos, son medios de información para que los servidores judiciales se enteren de actividades en las que tienen derecho a participar por ser organizadas y ejecutadas por el centro de formación y capacitación del poder judicial. Se trata de una expresión del derecho de acceso a la información entendido como la facultad de acceder a datos en poder del Estado así como de entes privados que efectúen gasto público y ejerzan funciones de autoridad (GARCÍA, 86, 2011), criterio que se extiende a las expresiones del Poder Popular en Venezuela.

Además, la oficina de cooperación técnica cumple otra función que si bien se materializa en formato papel, puede ejecutarse con pleno valor jurídico mediante el uso de las TIC. Se trata de la firma de alianzas y convenios institucionales.

Una vez más, al no exigirse más que mensajes de datos con firma electrónica certificada, solo sería necesario que los signatarios, que en el caso de la ENM sería el director general, dispusieran de firma digital o electrónica certificada.

En este caso, no haría falta reunirse, ni enviarse el documento en papel con firma manuscrita y sello, sino que sería suficiente redactar el convenio de modo electrónico, firmarlo digitalmente, enviarlo por correo electrónico para que la otra parte repita el proceso y archivarlo en cada órgano o ente firmante a fin de consultarlo cuando se requiera. 
El uso de firma electrónica certificada solo se acarrearía un problema cuando alguna de las partes fuera extranjera y por tanto usare firma electrónica certificada no garantizada por un Proveedor de Servicios de Certificación debidamente acreditado ante la Superintendencia de Servicios de Certificación Electrónica. En este caso, pudiera tratarse de una firma electrónica avanzada que será valorada conforme a la sana crítica pero no gozará de la presunción legal de validez que permitiría equipararla a la firma manuscrita ${ }^{35}$.

\section{Conclusiones}

La actividad de la ENM está condicionada por la celebración de procedimientos, actos y contratos, de naturaleza administrativa; vale decir, con trámites que deben cumplir con requisitos formales cuya materialización, es jurídicamente válida, mediante el uso de TIC.

Si bien existe una metodología de trabajo común a través del expediente administrativo y el punto de cuenta, que por estar integrados solo por escritos pueden llevarse al ámbito digital, mediante mensajes de datos con firma electrónica certificada, es importante tener presente que cada procedimiento tiene particularidades que igualmente son ejecutables en un entorno digital, y que aun para los casos en los que se requieran elementos tangibles, estos pueden incorporarse al expediente en cuadernos separados.

Así, las direcciones de docencia y secretaría realizan actividades en las que se debe incorporar un sistema informático para sustituir las listas de asistencia, que a falta de un programa que permita suplir las firmas manuscritas, lo que pudiera llevarse a cabo mediante la firma electrónica certificada del participante o mediante algún lector biométrico, sirven soluciones más rudimentarias como fotografiar a los presentes con su cédula de identidad y luego, agrupar todas la fotos en un archivo que firmará el responsable de la oficina o hacerlo usando un celular con la opción de geolocalización activada y que el referido responsable autentique los archivos con su firma electrónica certificada.

Igualmente, en los casos de actos administrativos complejos, solo faltaría promover y propiciar encuentros para exponer el deber legal de la Administración Pública de actuar en formato digital y de interoperar, sin pedir datos de autoría que pudieran ser intercambiados de modo digital.

En definitiva, aunque la ENM no cuenta con los medios informáticos idóneos para migrar al modelo administrativo "cero papel", puede basarse en las mismas herramientas tecnológicas existentes para lograr una gestión telemática, que redundará

35 Artículo 44 del DLMDFE: “...Los certificados electrónicos extranjeros, no garantizados por un Proveedor de Servicios de Certificación debidamente acreditado conforme a lo previsto en el presente DecretoLey, carecerán de los efectos jurídicos que se atribuyen en el presente Capítulo, sin embargo, podrán constituir un elemento de convicción valorable conforme a las reglas de la sana crítica". 
en mayor comodidad y celeridad para sus usuarios, en especial, los estudiantes, sobre todo, del interior del país.

\section{Referencias bibliográficas}

ALFONSO, Juan. La simplificación de trámites administrativos y la eventual reforma de la Ley Orgánica de Procedimientos Administrativos. Consideraciones sobre la Administración Electrónica. Boletín Electrónico de Derecho Administrativo. Venezuela: Universidad Católica "Andrés Bello", 2017.

AMONI, Gustavo. Las tecnologías de información y comunicación en las diversas formas de la actividad administrativa. Trabajo especial de grado para optar al título de especialista en Derecho Administrativo. Disponible en http://w2.ucab.edu.ve, 2010.

AMONI, Gustavo. Estado actual de la Administración electrónica en Venezuela. Memorias del XV Congreso Iberoamericano de Derecho e informática (T. 1), Argentina: eldial.com-FIADI, 2011. Disponible en: http://www.hfernandezdelpech.com.ar/TOMOI-MEMORIAS.doc.

AMONI, Gustavo. Trámites empresariales en la administración electrónica venezolana. En: CARRASCO, Felipe (Coord.). Derecho informático empresarial, México: Popocatépetl, 2013.

AMONI. Gustavo. El Procedimiento Administrativo a partir del Decreto Ley de Interoperabilidad y la Ley de Infogobierno. Revista Venezolana de Legislación y Jurisprudencia (7), 2016.

AMOROSO, Yarina. Open Data: una contribución necesaria al gobierno electrónico y la sociedad del conocimiento. En: REYES, Patricia (Coord). Ciudadanas 2020. El gobierno de la información. Chile: Instituto Chileno de Derecho y Tecnologías, 2011.

ARANGO, Adriana. Aproximación a la formación de contratos en Internet. Comercio electrónico. Colombia: Legis, 2005

ARCILA, Carlos y DE LA BARRA, Rodrigo. Aspectos legales del Gobierno Electrónico en Venezuela. Anuario electrónico de estudios en Comunicación Social "Disertaciones" (Vol. 2, n. 1). Colombia: Universidad del Rosario, 2009. Consultado en: https://revistas.urosario.edu.co/index.php/disertaciones/article/view/4287/3116\#_ftn26

BELANDRIA, José Rafael. El procedimiento administrativo telemático. Boletín Electrónico de Derecho Administrativo. (3), Caracas, 2017.

CANO, Jeimy. Evidencia digital: conceptos y retos. Comercio electrónico. Colombia: Legis, 2005. 
CHACÓN, Nayibe. Los principios de las TIC's aplicados a viejos conceptos. En: REYES, Patricia (Coord). Ciudadanas 2020. El gobierno de la información. Chile: Instituto Chileno de Derecho y Tecnologías, 2011.

FLORES, Lucerito. Derecho Informático. México: Grupo Editorial Patria, 2009.

GARCÍA, Myrna. La información pública es de todos. En: REYES, Patricia (Coord). Ciudadanas 2020. El gobierno de la información. Chile: Instituto Chileno de Derecho y Tecnologías, 2011.

GARCÍA, Myrna. La interoperabilidad en la justicia electrónica. EL tribunal virtual de Nuevo León. En: REYES, Patricia (Coord). Ciudadanas 2020 II. El gobierno de la información. Chile: Instituto Chileno de Derecho y Tecnologías, 2013.

GILLES, William. Le processus des gouvernements ouverts en France: Genèse d'un movement recent porté par des fondements plus anciens. International Journal of Open Governments, vol. 5, 2017.

GUERRERO, Jaqueline. Gobierno electrónico en Ecuador: realidad y desafíos, a la luz de la Carta Iberoamericana de Gobierno Electrónico. Ciudadanas 2020. El gobierno de la información. Chile: Instituto Chileno de Derecho y Tecnologías, 2011.

GUTIÉRREZ, Clara. Consideraciones sobre el tratamiento jurídico del comercio electrónico. Comercio electrónico. Colombia: Legis, 2005.

HERNÁNDEZ, José Ignacio. El contrato administrativo en la Ley de Contrataciones Públicas venezolana. Revista de Administración Pública (176), España, 2008.

HERNÁNDEZ, José Ignacio. El control judicial de la Administración electrónica. Comentarios a la sentencia de la Sala Político-Administrativa del 15 de diciembre de 2011. En: Revista de Derecho Público, n. 131, Caracas: Editorial Jurídica Venezolana, 2012.

HUSSMANN, Karen. La promesa de las compras públicas electrónicas: el caso de Chilecompra, Chile: Universidad de Chile, 2004.

LIMBERGER, Temis y LOPES, Maria. Cibertransparencia en la Administración Pública: la importancia de la cultura presupuestaria para concretización de los derechos sociales. Ciudadanas 2020. El gobierno de la información. Chile: Instituto Chileno de Derecho y Tecnologías, 2011.

LLAMAS, Miguel. El expediente administrativo electrónico y su incidencia en el control de la actuación administrativa. Fodertics, estudios sobre Derecho y Nuevas Tecnologías. España: andavira, 2012.

MELO, Luis Carlo F. de; OLIVEIRA, Marcela R. de. O perfil da Administracao Pública no século XXI: uma releitura à luz dos direitos fundamentais. Revista Digital de Direito Administrativo, vol. 5, n. 2, p. 97-118, 2018 
NAHABETIÁN, Laura. Gobernanza electrónica y gobierno electrónico: prácticas hacia la concreción del gobierno abierto. EN: REYES, Patricia (COORD). Ciudadanas 2020. El gobierno de la información. Chile: Instituto Chileno de Derecho y Tecnologías, 2011.

MORENO, Miguel. Contratos electrónicos. Derecho Civil Hoy: España, 1999.

NERI, Francescha del. Il documento amministrativo informatico: un cammino per approssimazione. Criticità e risposte possibili, tra normativa e prassi, dalla formazione alla conservazione. Italia: jlist.it, 2017.

PELLEGRINO, Cosimina. La necesidad de replantear la noción del acto administrativo en un mundo virtual (Una propuesta para la reforma de la Ley Orgánica de Procedimientos Administrativos). Revista Venezolana de Legislación y Jurisprudencia. ( $\left.\mathrm{N}^{\circ} 3\right)$, Caracas, 2014.

REYES, Patricia. La sociedad red y el gobierno de la información. Ciudadanas 2020. El gobierno de la información. Chile: Instituto Chileno de Derecho y Tecnologías, 2011.

REMOLINA, Nelson. Data Protection: aproximación global con énfasis en el caso colombiano. Revista Derecho y Tecnología (4), Venezuela: Universidad Católica del Táchira, 2004.

RICO, Mariliana. Las tecnologías de la información y comunicación en la actividad gubernamental. Ciudadanas 2020. El gobierno de la información. Chile: Instituto Chileno de Derecho y Tecnologías, 2011.

RÍOS, Wilson. Aspectos legales del software libre o de código abierto (Open source). Comercio electrónico. Colombia: Legis, 2005

SIRA, Gabriel. Algunas notas sobre la Ley de Infogobierno y el gobierno electrónico en Venezuela. Revista Electrónica de Derecho Administrativo Venezolano (6), 2015,

SOTO, Roberto y QUIÑóNEZ, Víctor. Estudio de las adquisiciones del estado y tecnologías de información: el caso del sistema electrónico de contrataciones del Estado en Perú. Ciencia y Tecnología, Año 12, № 1, 2016, 129-144

SOUZA de, Allison. Análise comparada das leis gerais de processo administrativo da Espanha e do Brasil à luz da sustentabilidade. Revista Digital de Direito Administrativo, vol. 3, n. 1, 2016.

TORREALBA, Miguel Ángel. Las actuaciones bilaterales: los contratos públicos y los convenios en la Ley Orgánica de la Jurisdicción Contencioso Administrativa, en HERNÁNDEZ-MENDIBLE, Víctor (Coord.). La actividad e inactividad administrativa y la jurisdicción contencioso administrativa. Caracas: editorial jurídica venezolana, 2012.

VELANDIA, Rómulo. El documento electrónico y sus dificultades probatorias. Caracas: Editorial Jurídica Venezolana, 2015. 
ZUBIETA, Hermann. Los mensajes de datos y las entidades de certificación. Comercio electrónico. Colombia: Legis, 2005. 